\title{
The Role of Tripartite Motif Family Proteins in TGF- $\beta$ Signaling Pathway and Cancer
}

\author{
Ho-Jae Lee \\ Department of Biochemistry, Lee Gil Ya Cancer and Diabetes Institute, Gachon University College of Medicine, Incheon, Korea
}

\begin{abstract}
TGF- $\beta$ signaling plays a tumor suppressive role in normal and premalignant cells but promotes tumor progression during the late stages of tumor development. The TGF- $\beta$ signaling pathway is tightly regulated at various levels, including transcriptional and post-translational mechanisms. Ubiquitination of signaling components, such as receptors and Smad proteins is one of the key regulatory mechanisms of TGF- $\beta$ signaling. Tripartite motif (TRIM) family of proteins is a highly conserved group of E3 ubiquitin ligase proteins that have been implicated in a variety of cellular functions, including cell growth, differentiation, immune response, and carcinogenesis. Recent emerging studies have shown that some TRIM family proteins function as important regulators in tumor initiation and progression. This review summarizes current knowledge of TRIM family proteins regulating the TGF- $\beta$ signaling pathway with relevance to cancer.
\end{abstract}

(J Cancer Prev 2018;23:162-169)

Key Words: Tripartite motif proteins, Transforming growth factor beta, Neoplasms

\section{INTRODUCTION}

TGF- $\beta$ is a pleiotropic cytokine that involved in a variety of cellular functions. The TGF- $\beta$ signaling pathway plays a pivotal role in regulating cellular responses including cell growth, apoptosis, differentiation, migration and metastasis in a context-dependent manner. ${ }^{1}$ Dysregulation of TGF- $\beta$ signaling pathway has been implicated in numerous human diseases, including cancer. ${ }^{2}$ In particular, TGF- $\beta$ signaling plays a crucial but paradoxical role in cancer. In early stages of tumor development, TGF- $\beta$ acts as a tumor suppressor, whereas in later stages, cancer cells become resistant to the growth inhibitory effect of TGF- $\beta$, TGF- $\beta$ can switch to tumor promoter. ${ }^{3}$ In later stages of cancer progression, TGF- $\beta$ promotes epithelial-mesenchymal transition (EMT), angiogenesis and suppression of immune surveillance. ${ }^{4.5}$ The TGF- $\beta$ signaling pathway is strictly regulated at various levels including the processing and availability of extracellular ligands, transcriptional control by coactivator and corepressor, and the post-translational modification of signaling components. ${ }^{6-8}$ TGF- $\beta$ receptors and Smads are well known to be downregulated via ubiquitination by E3 ubiquitin ligases. ${ }^{9}$

Tripartite motif (TRIM) family proteins are evolutionarily conserved proteins that are implicated in a number of cellular processes including proliferation, transcriptional regulation, differentiation, and cancer. ${ }^{10,11}$ The most typical feature of TRIM family is the highly conserved order of domains in the N-terminal RBCC motif, which contains a really interesting new gene (RING) domain, one or two B-box motifs, and a coiled-coil (CC) region. ${ }^{12}$ TRIM family proteins contain a RING domain, which can confer E3 ubiquitin ligase activity ${ }^{13}$ that mediates post-translational modifications of various cancer-associated proteins. In fact, some TRIM proteins are implicated in various aspects of tumorigenesis, including proliferation, apoptosis, transcriptional regulation, chromatin remodeling, invasion, and metastasis. ${ }^{14,15}$

Recent studies have shown that several members of TRIM proteins are implicated in the regulation of TGF- $\beta$ signaling

Received December 3, 2018, Revised December 18, 2018, Accepted December 18, 2018

Correspondence to: Ho-Jae Lee

Department of Biochemistry, Gachon University College of Medicine, 155 Gaetbeol-ro, Yeonsu-gu, Incheon 21999, Korea

Tel: +82-32-899-6054, Fax: +82-32-899-6039, E-mail: hojlee@gachon.ac.kr, ORCID: Ho-Jae Lee, https://orcid.org/0000-0003-2170-355X

Copyright (c) 2018 Korean Society of Cancer Prevention

(c) This is an Open Access article distributed under the terms of the Creative Commons Attribution Non-Commercial License (http://creativecommons.org/licenses/by-nc/4.0) which permits unrestricted non-commercial use, distribution, and reproduction in any medium, provided the original work is properly cited. 
pathway. This review focuses on the regulatory role of TRIM proteins in TGF- $\beta$ pathway identified so far and further discusses how the TRIM protein-associated TGF- $\beta$ signaling pathway affects cancer progression.

\section{TRIPARTITE MOTIF FAMILY PROTEINS}

TRIM family comprises more than 80 members in human that is characterized by the presence of a TRIM, which consists of a RING domain, followed by one or two zinc-finger domains named B-boxes (B1 and B2), and a CC region in the N-terminal region. ${ }^{12}$ TRIM family proteins are implicated in a broad range of cellular processes, including intracellular signaling, protein quality control, innate immunity, inflammation, and carcinogenesis. ${ }^{14}$

\section{Structure of tripartite motif proteins}

The N-terminal RBCC domains are aligned in the same order, as shown in Figure 1, implying a modular function of the TRIM. The
RING domain, a zinc finger motif, has been found in many functionally diverse proteins and shown to play an important role in ubiquitination of target proteins. ${ }^{13}$ The B-box domains are also zinc-binding motifs which are supposed to act as protein-protein interaction domains and thereby determine the substrate specificity of RING-finger E3 ubiquitin ligase. The CC region that spans approximately 100 residues is thought to mediate homo- and hetero-interactions between TRIMs and other proteins. ${ }^{11}$

The N-terminal TRIM domain is usually followed by one or two C-terminal domains of variable length and composition. There are 10 different types of C-terminal domain, and the TRIM family has been classified into 11 subgroups according to their different C-terminal domains alone or in combination (Fig. 1). ${ }^{12}$

The most common C-terminal domain that expressed by TRIM proteins is PRY or SPRY sequence. The SPRY domain is often linked to the PRY domain to form the PRY-SPRY domain. The PRY-SPRY domain, also known as B30. The 2 domain, has been

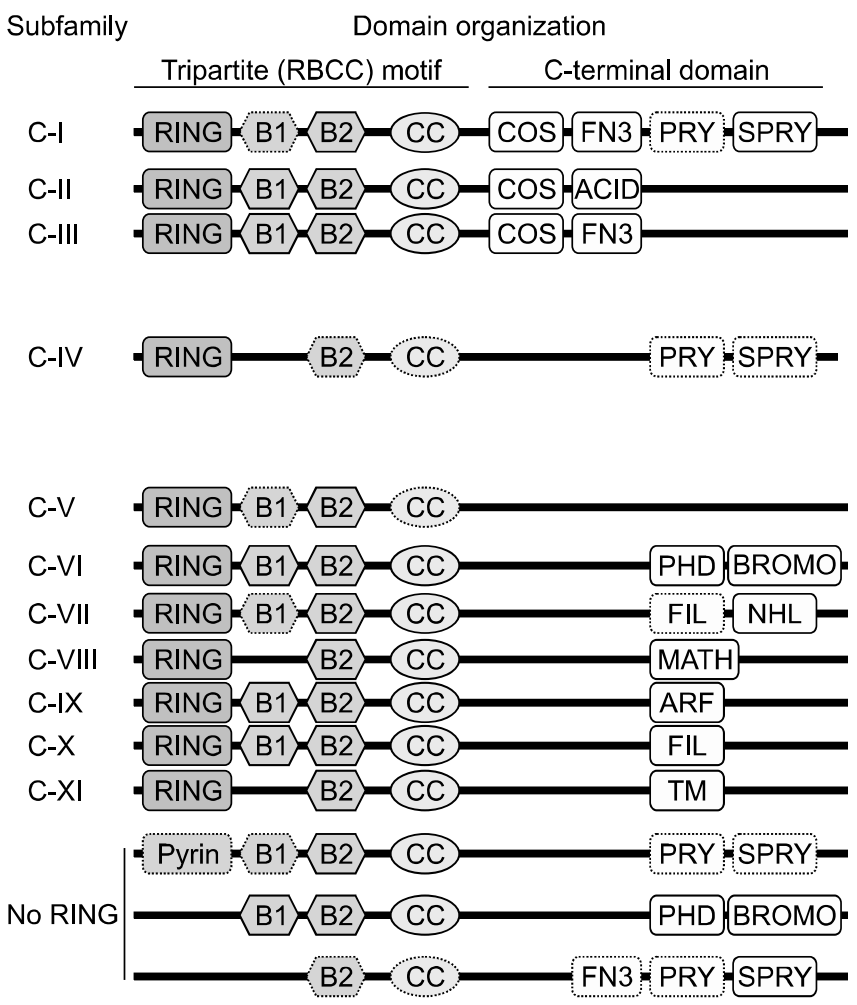

Subfamily members

TRIM1, TRIM9, TRIM18, TRIM36

TRIM46 ( $\Delta \mathrm{B} 1)$, TRIM67 ( $\triangle \mathrm{PRY})$

TRIM54, TRIM55, TRIM63

TRIM42

TRIM4, TRIM5, TRIM6, TRIM10, TRIM11, TRIM15, TRIM17, TRIM21, TRIM22, TRIM25, TRIM26, TRIM27, TRIM34, TRIM35, TRIM38, TRIM39, TRIM41, TRIM43, TRIM47 ( $\triangle$ SPRY), TRIM48, TRIM49, TRIM50, TRIM51 ( $\Delta$ B2, $\Delta$ PRY), TRIM53, TRIM58, TRIM60, TRIM62, TRIM64, TRIM65 ( $\triangle \mathrm{PRY})$, TRIM68, TRIM69, TRIM72, TRIM75, TRIM77 (B1, PRY), TRIML1 ( $\triangle \mathrm{B} 2)$

TRIM8, TRIM19 , TRIM31, TRIM40, TRIM52 TRIM56, TRIM61 ( $\Delta \mathrm{B} 1, \Delta \mathrm{CC})$, TRIM73, TRIM74

TRIM24, TRIM28, TRIM33

TRIM2, TRIM3 ( $\Delta \mathrm{B} 1)$, TRIM32 ( $\Delta \mathrm{B} 1, \Delta \mathrm{FIL})$, TRIM71

TRIM37

TRIM23

TRIM45

TRIM13, TRIM59

TRIM14, TRIM16 ( $\Delta$ Pyrin), TRIM20, TRIM29

TRIM44 ( $\triangle$ Pyrin, $\Delta \mathrm{B} 1, \Delta \mathrm{PRY}, \Delta \mathrm{SPRY})$

\section{TRIM66}

TRIM70 ( $\Delta \mathrm{B} 2, \Delta \mathrm{CC}, \Delta \mathrm{FN} 3)$, TRIM76, TRIML2 $(\Delta \mathrm{B} 2, \Delta \mathrm{FN} 3, \Delta \mathrm{PRY})$

Figure 1. The structural classification of tripartite motif (TRIM) family proteins. Most of TRIM proteins contain a really interesting new gene (RING) finger domain, one or two B-box domain (B1 and B2) and a coiled-coil (CC) domain in N-terminal region. TRIM proteins are classified into 11 subfamilies (C-I to C-XI) based on a variable C-terminal domain. There is an additional unclassified group lacking a RING finger domain (No RING). Some TRIM family members lack one or more domain as denoted in brackets and by a dashed outline. TRIM proteins described in this review are in bold. Pyrin, Pyrin domain; COS, cos-box; FN3, fibronectin type III repeat; PRY, PRY domain; SPRY, SPRY domain; ACID, acid-rich region; PHD, PHD domain; BROMO, bromodomain; FIL, filamin-type immunoglobulin domain; NHL, NCL1, HT2A and LIN41 domain; MATH, meprin and TRAF-homology domain; ARF, ADP-ribosylation factor family domain; TM, transmembrane region. 
shown to play an important role in immune regulation. ${ }^{16}$ Other domains present in C-terminal region include the cos-box, fibronectin type 3 domain, plant homeodomain (PHD) zinc finger and bromodomain. The PHD zinc finger and bromodomain are commonly found in nuclear proteins and associated with chromatin remodeling and chromatin-mediated transcriptional regulation. ${ }^{17}$ The divergent $\mathrm{C}$-terminal domains might contribute to the functional diversity of TRIM family proteins.

\section{Role of tripartite motif family proteins in cancer}

TRIM family proteins are involved in a wide range of biological processes, and their altered expression or aberrant function leads to various pathological conditions, such as developmental diseases, infectious diseases, and neurodegenerative diseases. ${ }^{18,19}$ Recently, a number of studies have shown that some TRIM family members are implicated in carcinogenesis and tumor progression. ${ }^{15}$

It has been known for many years that four TRIM family genes, TRIM19, TRIM24, TRIM27, and TRIM33, are frequently translocated to the loci of known oncogenes in different types of tumors and are involved in cancer initiation and progression. ${ }^{20}$ Among these, the most famous is TRIM19, also known as promyelocytic leukemia, which is fused to retinoic acid receptor $\alpha(\operatorname{RAR} \alpha)$ in acute promyelocytic leukemia. ${ }^{20}$ TRIM24, also known as transcriptional intermediary factor $1 \alpha$ (TIF1- $\alpha$ ) belongs to the TIF1 subgroup of TRIM family members which includes, TRIM28 (TIF1ß), TRIM33 (TIF1 $\gamma$ ), and TRIM66 (TIF18). ${ }^{21}$ TRIM24 can be fused to BRAF in hepatocellular carcinoma and Ret receptor tyrosine kinase in papillary thyroid carcinoma. ${ }^{22,23}$ Furthermore, TRIM24 has been shown to play a role as either promoting or suppressing tumor development depending on the cell type or context. The expression of TRIM24 is upregulated in breast cancer tissues and directly correlated with poor prognosis in both estrogen receptor-positive and -negative breast cancers. ${ }^{24}$ However, TRIM24 can suppress the RAR $\alpha$-mediated transcriptional activity, and thereby preventing hepatic tumor growth. ${ }^{25}$ TRIM24 deficiency resulted in a high incidence of spontaneous hepatic tumor formation and lung metastasis.

The highly conserved RING domain confers E3 ubiquitin ligase activity to most members of the TRIM family, and ubiquitination of substrate proteins appears to be one of the key mechanisms by which TRIM proteins exert their biological functions. ${ }^{17}$ Ubiquitination is one of the most prevalent post-translational modifications that regulate various signaling pathways and cellular functions. The ubiquitin-mediated proteolytic pathway has a pivotal role in quality control of proteins or elimination of short-lived regulatory proteins including those that participate in cell cycle, cellular signaling, and transcriptional regulation. ${ }^{20}$

Some members of TRIM family can control carcinogenesis by modulating the stability or functional activity of $\mathrm{p} 53$, which is one of the most important tumor suppressor proteins. Joo et $\mathrm{al}^{26}$ demonstrated that TRIM13 increases ubiquitination and proteasomal degradation of mouse double minute 2 (Mdm2), which targets $\mathrm{p} 53$ for degradation. It has been reported that TRIM19 enhances the stabilization of $\mathrm{p} 53$ by binding and sequestering Mdm2 protein to the nucleus. ${ }^{27}$ These results imply that TRIM13 and TRIM19 can function as tumor suppressors by positively regulating $\mathrm{p} 53$ activity.

On the other hand, other TRIM proteins including TRIM24, TRIM28, TRIM29, and TRIM39 act as negative regulators of p53. TRIM24, as an E3 ubiquitin ligase, has also been identified as a p53-binding protein by mass spectrometry. ${ }^{28}$ TRIM24 directly ubiquitinates $\mathrm{p} 53$ via RING domain and negatively regulates p53 function, indicating that TRIM24 is a therapeutic target to restore tumor suppression by p53. TRIM28, also known as TIF1 $\beta$ and Krüppel-associated box (KRAB)-associated protein 1 (KAP1) was identified as a Mdm2-interacting protein and targets the p53 for proteasomal degradation via interaction with $\mathrm{Mdm} 2 .{ }^{29}$ Another TRIM protein, TRIM29, which lacks a RING domain and has no E3 ubiquitin ligase activity, associates with $\mathrm{p} 53$ and sequestrates it in the cytoplasm thus inhibiting p53-dependent transcriptional activation. ${ }^{30}$ In addition, Sho et al. ${ }^{31}$ demonstrated that TRIM29 promotes degradation of Tat-interactive protein 60 (Tip60), which has histone acetyltransferase activity, resulting in the abrogation of p53 acetylation mediated by Tip60. By suppressing p53 activity, TRIM29 enhances cell growth and transforming activity. These findings suggested that TRIM29 may act as an oncogene that promotes tumor growth. TRIM39 can also directly bind and ubiquitinate p53 and targets it for degradation in a RINGdependent manner, indicating that TRIM39 acts as a negative regulator of $\mathrm{p} 533^{32}$

Besides the p53 regulation, several other TRIM proteins are implicated in a variety of cancer signaling pathways. For example, TRIM32 expression is upregulated in breast tumor tissues and increases cell growth through activation of the NF- $\mathrm{kB}$ signaling pathway. ${ }^{33}$ TRIM32 also promotes cell proliferation and invasion of gastric or lung cancer cells by activating $\beta$-catenin or JAK2/STAT3-signaling pathway, respectively. ${ }^{34,35}$ Also, some TRIM family proteins have been reported to play roles in the regulation of the TGF- $\beta$ signaling pathway. 


\section{INVOLVEMENT OF TRIPARTITE MOTIF FAMILY PROTEINS IN TGF- $\beta$ SIGNALING}

TGF- $\beta$ signaling is regulated in both positive and negative manners, and is tightly controlled temporally and spatially by various mechanisms. ${ }^{36}$ Positive regulation can contribute to the amplification and sustaining of the TGF- $\beta$ signaling. Negative regulation plays a critical role in restriction and termination of TGF- $\beta$ signaling primarily through a negative feedback loop. TRIM family proteins have been shown to both positively and negatively regulate TGF- $\beta$ signaling (Table 1 ).

\section{Negative regulation by tripartite motif family proteins}

The core TGF- $\beta$ signaling components, TGF- $\beta$ receptors and Smads, are shown to be downregulated by protein ubiquitination and subsequent degradation in proteasome. ${ }^{37-39}$ Ectodermin, the Xenopus ortholog of mammalian TRIM33, also denominated as TIF1- $\gamma$, was one of the first proposed TRIM family members to function as a negative regulator of TGF- $\beta$ signaling. The RING-type E3 ubiquitin ligase TRIM33 was shown to restrict the mesoderm-inducing activity of TGF- $\beta$ and favor the specification of ectoderm. ${ }^{40}$ This activity was demonstrated to be dependent on the ubiquitination of Smad4 by TRIM33, which leads to degradation of Smad4 and inhibits TGF- $\beta$ signaling. TRIM33 also monoubiquitinates Smad4 at lysine 519 in its Mad homology (MH) 2 domain, which promotes nuclear export of Smad4, thus destabilizes the functional nuclear Smad complex formation. ${ }^{41}$ The functional inactivation of Smad4 has been closely linked to human cancers including pancreatic and colorectal carcinoma. ${ }^{42}$ Vincent et $\mathrm{al}^{4}{ }^{43}$ showed that TRIM33 works with Smad as a complementary agonist molecule during pancreatic carcinogenesis. Although the relationship between TRIM33 and Smad4 in cancer is unclear, TRIM33 may act as a negative regulator of TGF- $\beta$ signaling through antagonizing the transcription coactivator role of Smad4.

Beside the inhibitory effect of TRIM33 on TGF- $\beta$ signaling, TRIM33 also has been identified as a binding partner of Smad2 and Smad3 in response to TGF- $\beta$, and promoting Smad4independent signaling pathway. ${ }^{44}$ Interaction of $\operatorname{Smad} 2 / 3$ with TRIM33 stimulates erythroid differentiation of hematopoietic stem cells, whereas interaction of Smad2/3 with Smad4 inhibits the proliferation of these cells in response to TGF- $\beta$. TRIM33 (TIF1- $\gamma$ ) and other TIF family members are characterized by the presence of a PHD zinc finger and a bromodomain in the C-terminal region of the protein. The PHD and bromodomain are known to recognize post-translational modifications on histone. ${ }^{45}$ Agricola et $\mathrm{al}^{46}$ demonstrated that TRIM33 is recruited to chromatin upon TGF- $\beta$ stimulation and the E3 ubiquitin ligase activity of TRIM33 is induced by binding of TRIM33 to histones via its PHD zinc finger-bromodomain to modified histones. The monoubiquitination of Smad4 disrupts chromatin-bound Smad complexes, and TRIM33 is responsible for dictating the residence time of Smad complexes at TGF- $\beta$-regulated enhancers. ${ }^{47} \mathrm{Xi}$ et $\mathrm{al}^{48}$ demonstrated that TRIM33 activates nodal signaling by complexing of TRIM33 with receptor-activated Smads and binding to poised chromatin to displace the chromatincompacting factor, chromobox protein homolog 3 . These results

Table 1. TRIM family proteins associated with TGF- $\beta$ signaling pathway

\begin{tabular}{|c|c|c|}
\hline TRIM & Involvement in TGF- $\beta$ signaling pathway & Reference No. \\
\hline TRIM11 & Suppression of TGF- $\beta$-mediated MED15 function & 59 \\
\hline TRIM25 (EFP) & Smad activation and promotion of migration & 65 \\
\hline TRIM26 & Transcriptional induction of TRIM 26 by TGF- $\beta$ & 67 \\
\hline TRIM28 (TIF1 $\beta)$ & Promotion of TGF- $\beta$-induced EMT and migration & 68 \\
\hline \multirow[t]{5}{*}{ TRIM33 (TIF $1 \gamma)$} & Ubiquitination and degradation of Smad4 & 40 \\
\hline & Monoubiquitination of Smad4 & 41 \\
\hline & Stimulation of TGF- $\beta$-induced erythroid differentiation by TRIM33/Smad $2 / 3$ complex & 44 \\
\hline & Ubiquitination of Smad4 requires histone modification & 46 \\
\hline & Activation of nodal signaling by TRIM33/Smad2/3 complex & 48 \\
\hline TRIM59 (MRF1) & Depletion of TRIM59 reduces TGF- $\beta$ and Smad activation & 75,76 \\
\hline TRIM62 (DEAR1) & Ubiquitination and degradation of Smad3 & 56 \\
\hline TRIM66 (TIF1 $\delta)$ & Promotion of TGF- $\beta$-induced EMT & 71 \\
\hline \multirow[t]{2}{*}{ TRIM72 (MG53) } & Depletion of TRIM72 reduces TGF- $\beta$ and type I receptor & 78 \\
\hline & Inhibition of TGF- $\beta$-induced myofibroblast differentiation & 79 \\
\hline
\end{tabular}

TRIM, tripartite motif; EFP, estrogen-responsive finger protein; TIF1, transcriptional intermediary factor 1; MRF1, mouse ring finger 1; DEAR1, ductal epithelium-associated RING Chromosome 1; MG53, mitsugumin 53; MED15, mediator of RNA polymerase II transcription subunit 15; EMT, epithelial mesenchymal transition. 
implied that the transcription factors Smads can regulate gene expression by initially detecting histone marks as a platform to switch master regulators of cell differentiation from the poised to the active state.

TRIM62, also known as ductal epithelium-associated RING Chromosome 1, is a tumor suppressor gene which maps to chromosome 1p35, a region that frequently deleted in a broad range of human cancers. ${ }^{49}$ TRIM62 is expressed in the ductal and glandular epithelium of normal mammary and other tissues and functioned as a dominant regulator of acinar morphogenesis in the mammary glands. ${ }^{50}$ The TGF- $\beta$ signaling is one of the most frequently deregulated pathways in breast cancer and also associated with tumor malignancy. ${ }^{51}$ TRIM62 is a member of the TRIM/RBCC family and has a RING finger E3 ubiquitin ligase activity. $^{52}$ TRIM62 gene has been found mutated in breast and other epithelial cancers and its low expression is correlated with poor clinical prognosis. ${ }^{53-55}$ Chen et al..$^{56}$ demonstrated that TRIM62 acts as chromosome 1p35 tumor suppressor and negative regulator of TGF- $\beta /$ Smad signaling. TRIM62 specifically binds to the linker and MH2 domains of Smad3 and promotes the ubiquitination and degradation of Smad3. These resulted in a decrease in TGF- $\beta /$ Smad3 target genes, including Snail1 and Snail2, which act as master transcriptional regulators of EMT. These data implied that TRIM62 acts as an important regulator of TGF- $\beta$-induced EMT and might be a potential biomarker for clinical strategies that target the TGF- $\beta /$ Smad3 signaling pathway.

\section{Positive regulation by tripartite motif family proteins}

TRIM11 is shown to be highly expressed in glioma and lung cancer tissues and correlated with poor prognosis. ${ }^{57.58}$ Ishikawa et al. ${ }^{59}$ showed that TRIM1 1 suppresses TGF- $\beta$-induced transcription of transcriptional cofactor mediator of RNA polymerase II transcription subunit 15 (MED15). MED15, also known as ARC105, is a component of activator-recruited cofactor complex that mediates chromatin-directed transcriptional activation. ${ }^{60.61}$ MED15 has been shown to play a key role in TGF- $\beta /$ activin/nodal signaling in Xenopus laevis axis formation and mesendoderm differentiation. ${ }^{62}$ MED15 also interacts with Smad2/3 and Smad4 in response to TGF- $\beta$ stimulation. TRIM11 interacts and destabilizes MED15 through the ubiquitin-proteasome dependent degradation pathway. Recently, Zhao et al. ${ }^{63}$ showed that MED15 deficiency attenuates the TGF- $\beta$-targeted gene expression and inhibits TGF- $\beta$-induced EMT, through the inhibition of receptor-activated Smad activation.

TRIM25 was initially identified as estrogen-responsive finger protein that is essential for cell proliferation and organ development in response to estrogen. ${ }^{64}$ It has recently been shown that TRIM25 is highly expressed in colorectal and gastric cancer tissues and promotes migration and invasion of cancer cells through activation of TGF- $\beta$ signaling pathway. ${ }^{65,66}$ The ectopic expression of TRIM25 in gastric and colorectal cancer cells increases Smad activation and cell migration.

Nakagawa et $a .^{67}$ demonstrated that TGF- $\beta$ induces the expression of E3 ubiquitin ligase TRIM26, and the induction of TRIM26 is mediated by direct binding of TGF- $\beta$-activated Smad3 to Smad binding elements in the TRIM26 promoter. TGF- $\beta$ induced growth arrest in mammary epithelial cells is mediated by TRIM26-dependent degradation of a general transcription factor IID subunit TATA box binding protein-associate factor 7 . These data suggested that TRIM26 is a direct target of Smad3, and is required for TGF- $\beta$-mediated growth inhibition.

Chen et al. ${ }^{68}$ found that TRIM28 promotes TGF- $\beta$-induced EMT, cell migration and invasion of lung cancer cells. The expression of TRIM 28 is induced by TGF- $\beta$ and leads to modulate the expression of EMT marker genes, such as $C d h 1$ and $C d h 2$ through modification of histones of target gene promoters. TRIM28 has also been specifically implicated in the EMT process in cancer cells via different mechanisms. ${ }^{69,70}$

TRIM66 (TIF18) contains two B-boxes and a CC domain and does not have a RING-finger domain in the N-terminal region ${ }^{21}$ Chen et al. ${ }^{71}$ found that TRIM66 is significantly increased in osteosarcoma tissues and the high expression level of TRIM66 is associated with lung metastasis and poor survival rate in patients with osteosarcoma. Gene Expression Omnibus database analysis indicated that EMT and TGF- $\beta$ signaling pathway-related genes are enriched in patients with high TRIM66 expression. These data suggested that TRIM66 acts as an oncogene through promoting TGF- $\beta$ signaling and TGF- $\beta$-induced EMT.

TRIM59, also known as mouse ring finger 1, belongs to the TRIM family, which has been implicated in the carcinogenesis of several human cancers, such as gastric, lung, and breast cancer. ${ }^{72-74}$ TRIM59 is highly expressed in bladder and breast cancer tissues and promotes migration and invasion through the TGF- $\beta /$ Smad2/3 signaling pathway. ${ }^{75,76}$ The downregulation of TRIM59 expression contributes to the inhibition of TGF- $\beta$ signaling pathway, consequently reducing levels of TGF- $\beta$ and Smad2/3 phosphorylation.

A muscle-specific TRIM family protein, TRIM72, also called mitsugumin 53 , has been shown to be expressed specifically in the plasma membrane of skeletal muscle, and it has a critical role in membrane repair after acute muscle injury. ${ }^{77}$ Zhao and Lei $^{78}$ 
showed that TRIM72 promotes the proliferation and migration of cardiac fibroblasts. The gene expression analysis demonstrated that TRIM72 regulates the expression of TGF- $\beta 1$ and TGF- $\beta$ type I receptor. On the other hand, TRIM72 plays a negative regulatory role during wound healing and fibrotic processes. Recombinant human TRIM72 inhibits the activation of Smad2/3 and TGF$\beta$-dependent activation of myofibroblast differentiation. ${ }^{79}$ These results suggest that the differential regulation of TGF- $\beta$ signaling by TRIM family proteins may have important implications in many physiological and pathological processes.

\section{CONCLUSION AND PERSPECTIVE}

As described in this review, many studies over the years have demonstrated that TRIM family proteins positively or negatively regulate the TGF- $\beta$ signaling pathway in various types of cancer. Complex signaling by TGF- $\beta$ regulates cancer initiation and progression through a cancer cell-autonomous mechanism or cancer-stroma interaction, and acts as either tumor suppressor or promoter in cell-type and context dependent manners. In line with the complex role of TGF- $\beta$ in cancer, TRIM proteins also modulate the TGF- $\beta$ signaling according to the cellular context by acting either positively or negatively. Most of TRIM family proteins have E3 ubiquitin ligase activity and contain different types of domains in the C-terminal region. Up to now, a few TRIM family proteins which interact with the signaling components of TGF- $\beta$ have been identified to date. Therefore, further analyses are required to determine whether other TRIM family proteins are involved in the TGF- $\beta$ signaling pathway. In addition, more detailed studies are needed to understand the role of TRIM protein-mediated regulation of TGF- $\beta$ signaling pathway and its implications in cancer initiation and progression. It is also needed more detailed biochemical analyses and genetic approaches to identify the specific role of TRIM proteins in the TGF- $\beta$ pathway and cancer. Achieving selectivity in targeting components will lead to potential strategies for treating cancers that result from deregulation of the TGF- $\beta$ signaling pathway.

\section{ACKNOWLEDGMENTS}

This work was supported by the Basic Science Research Program through the National Research Foundation of Korea (NRF) funded by the Ministry of Education, Science and Technology (NRF-2016R1D1A1B 03935001).

\section{CONFLICTS OF INTEREST}

No potential conflicts of interest were disclosed.

\section{REFERENCES}

1. Massagué J. TGF $\beta$ signalling in context. Nat Rev Mol Cell Biol 2012;13:616-30.

2. Massagué J, Blain SW, Lo RS. TGFbeta signaling in growth control, cancer, and heritable disorders. Cell 2000;103:295-309.

3. de Caestecker MP, Piek E, Roberts AB. Role of transforming growth factor-beta signaling in cancer. J Natl Cancer Inst 2000;92:1388-402.

4. Principe DR, Doll JA, Bauer J, Jung B, Munshi HG, Bartholin L, et al. TGF- $\beta$ : duality of function between tumor prevention and carcinogenesis. J Natl Cancer Inst 2014;106:djt369.

5. Katsuno Y, Lamouille S, Derynck R. TGF- $\beta$ signaling and epithelial-mesenchymal transition in cancer progression. Curr Opin Oncol 2013;25:76-84.

6. Moustakas A, Heldin $\mathrm{CH}$. The regulation of TGFbeta signal transduction. Development 2009:136:3699-714.

7. Lönn P, Morén A, Raja E, Dahl M, Moustakas A. Regulating the stability of TGFbeta receptors and Smads. Cell Res 2009;19:21-35.

8. Shi Y, Massagué J. Mechanisms of TGF-beta signaling from cell membrane to the nucleus. Cell 2003;113:685-700.

9. Inoue Y, Imamura T. Regulation of TGF-beta family signaling by E3 ubiquitin ligases. Cancer Sci 2008;99:2107-12.

10. Crawford LJ, Johnston CK, Irvine AE. TRIM proteins in blood cancers. J Cell Commun Signal 2018;12:21-9.

11. Napolitano LM, Meroni G. TRIM family: pleiotropy and diversification through homomultimer and heteromultimer formation. IUBMB Life 2012;64:64-71.

12. Ozato K, Shin DM, Chang TH, Morse HC 3rd. TRIM family proteins and their emerging roles in innate immunity. Nat Rev Immunol 2008;8:849-60.

13. Joazeiro CA, Weissman AM. RING finger proteins: mediators of ubiquitin ligase activity. Cell 2000;102:549-52.

14. Hatakeyama S. TRIM family proteins: roles in autophagy, immunity, and carcinogenesis. Trends Biochem Sci 2017;42:297-311.

15. Hatakeyama S. TRIM proteins and cancer. Nat Rev Cancer 2011;11:792-804.

16. D'Cruz AA, Babon JJ, Norton RS, Nicola NA, Nicholson SE. Structure and function of the SPRY/B30.2 domain proteins involved in innate immunity. Protein Sci 2013:22:1-10.

17. Aasland R, Gibson TJ, Stewart AF. The PHD finger: implications for chromatin-mediated transcriptional regulation. Trends Biochem Sci 1995:20:56-9.

18. Watanabe M, Hatakeyama S. TRIM proteins and diseases. J Biochem 2017;161:135-44.

19. Kawai T, Akira S. Regulation of innate immune signalling pathways by the tripartite motif (TRIM) family proteins. EMBO Mol Med 2011;3:513-27.

20. Hershko A, Ciechanover A. The ubiquitin system. Annu Rev Biochem 1998:67:425-79.

21. Khetchoumian K, Teletin M, Mark M, Lerouge T, Cerviño M, Oulad-Abdelghani $\mathrm{M}$, et al. TIF1delta, a novel HP1-interacting member of the transcriptional intermediary factor 1 (TIF1) fam- 
ily expressed by elongating spermatids. J Biol Chem 2004:279: 48329-41.

22. Klugbauer S, Rabes HM. The transcription coactivator HTIF1 and a related protein are fused to the RET receptor tyrosine kinase in childhood papillary thyroid carcinomas. Oncogene 1999;18:4388-93.

23. Le Douarin B, Zechel C, Garnier JM, Lutz Y, Tora L, Pierrat P, et al. The N-terminal part of TIF1, a putative mediator of the ligand-dependent activation function (AF-2) of nuclear receptors, is fused to B-raf in the oncogenic protein T18. EMBO J 1995;14:2020-33.

24. Chambon M, Orsetti B, Berthe ML, Bascoul-Mollevi C, Rodriguez C, Duong V, et al. Prognostic significance of TRIM24/TIF-1 $\alpha$ gene expression in breast cancer. Am J Pathol 2011;178:1461-9.

25. Khetchoumian K, Teletin M, Tisserand J, Mark M, Herquel B, Ignat $\mathrm{M}$, et al. Loss of Trim24 (Tiflalpha) gene function confers oncogenic activity to retinoic acid receptor alpha. Nat Genet 2007:39:1500-6.

26. Joo HM, Kim JY, Jeong JB, Seong KM, Nam SY, Yang KH, et al. Ret finger protein 2 enhances ionizing radiation-induced apoptosis via degradation of AKT and MDM2. Eur J Cell Biol 2011;90: 420-31.

27. Bernardi R, Scaglioni PP, Bergmann S, Horn HF, Vousden KH, Pandolfi PP. PML regulates $\mathrm{p} 53$ stability by sequestering $\mathrm{Mdm} 2$ to the nucleolus. Nat Cell Biol 2004;6:665-72.

28. Allton K, Jain AK, Herz HM, Tsai WW, Jung SY, Qin J, et al. Trim24 targets endogenous $\mathrm{p} 53$ for degradation. Proc Natl Acad Sci U S A 2009;106:11612-6.

29. Wang C, Ivanov A, Chen L, Fredericks WJ, Seto E, Rauscher FJ 3rd, et al. MDM2 interaction with nuclear corepressor KAP1 contributes to p53 inactivation. EMBO J 2005;24:3279-90.

30. Yuan Z, Villagra A, Peng L, Coppola D, Glozak M, Sotomayor EM, et al. The ATDC (TRIM29) protein binds $\mathrm{p} 53$ and antagonizes p53-mediated functions. Mol Cell Biol 2010;30:3004-15.

31. Sho T, Tsukiyama T, Sato $T$, Kondo $T$, Cheng J, Saku T, et al. TRIM29 negatively regulates $\mathrm{p} 53$ via inhibition of Tip60. Biochim Biophys Acta 2011;1813:1245-53.

32. Zhang L, Huang NJ, Chen C, Tang W, Kornbluth S. Ubiquitylation of p53 by the APC/C inhibitor Trim39. Proc Natl Acad Sci U S A 2012;109:20931-6.

33. Zhao TT, Jin F, Li JG, Xu YY, Dong HT, Liu Q, et al. TRIM32 promotes proliferation and confers chemoresistance to breast cancer cells through activation of the NF- $K \mathrm{~b}$ pathway. J Cancer 2018;9:1349-56.

34. Wang C, Xu J, Fu H, Zhang Y, Zhang X, Yang D, et al. TRIM32 promotes cell proliferation and invasion by activating $\beta$-catenin signalling in gastric cancer. J Cell Mol Med 2018;22:5020-8.

35. Yin H, Li Z, Chen J, Hu X. Expression and the potential functions of TRIM32 in lung cancer tumorigenesis [published online ahead of print October 30, 2018]. J Cell Biochem. doi: 10.1002/jcb. 27798.

36. Miyazono K. Positive and negative regulation of TGF-beta signaling. J Cell Sci 2000;113:1101-9.

37. Xu P, Lin X, Feng XH. Posttranslational regulation of Smads. Cold Spring Harb Perspect Biol 2016;8:a022087.

38. Xu P, Liu J, Derynck R. Post-translational regulation of TGF- $\beta$ receptor and Smad signaling. FEBS Lett 2012;586:1871-84.

39. Massagué J. TGFbeta in cancer. Cell 2008;134:215-30.

40. Dupont S, Zacchigna L, Cordenonsi M, Soligo S, Adorno M, Rugge $\mathrm{M}$, et al. Germ-layer specification and control of cell growth by Ectodermin, a Smad4 ubiquitin ligase. Cell 2005;121:87-99.
41. Dupont S, Mamidi A, Cordenonsi M, Montagner M, Zacchigna L, Adorno M, et al. FAM/USP9x, a deubiquitinating enzyme essential for TGFbeta signaling, controls Smad4 monoubiquitination. Cell 2009;136:123-35.

42. Zhao M, Mishra L, Deng CX. The role of TGF- $\beta / S M A D 4$ signaling in cancer. Int J Biol Sci 2018;14:111-23.

43. Vincent DF, Yan KP, Treilleux I, Gay F, Arfi V, Kaniewski B, et al. Inactivation of TIFlgamma cooperates with Kras to induce cystic tumors of the pancreas. PLoS Genet 2009:5:e1000575.

44. He W, Dorn DC, Erdjument-Bromage H, Tempst P, Moore MA, Massagué J. Hematopoiesis controlled by distinct TIF1gamma and Smad4 branches of the TGFbeta pathway. Cell 2006;125: 929-41.

45. Ruthenburg AJ, Li H, Patel DJ, Allis CD. Multivalent engagement of chromatin modifications by linked binding modules. Nat Rev Mol Cell Biol 2007;8:983-94.

46. Agricola E, Randall RA, Gaarenstroom T, Dupont S, Hill CS. Recruitment of TIF $1 \gamma$ to chromatin via its PHD finger-bromodomain activates its ubiquitin ligase and transcriptional repressor activities. Mol Cell 2011;43:85-96.

47. Gaarenstroom T, Hill CS. TGF- $\beta$ signaling to chromatin: how Smads regulate transcription during self-renewal and differentiation. Semin Cell Dev Biol 2014:32:107-18.

48. Xi Q, Wang Z, Zaromytidou AI, Zhang XH, Chow-Tsang LF, Liu JX, et al. A poised chromatin platform for TGF- $\beta$ access to master regulators. Cell 2011;147:1511-24.

49. Bagchi A, Mills AA. The quest for the 1 p36 tumor suppressor. Cancer Res 2008:68:2551-6.

50. Lott ST, Chen N, Chandler DS, Yang Q, Wang L, Rodriguez M, et al. DEAR1 is a dominant regulator of acinar morphogenesis and an independent predictor of local recurrence-free survival in early-onset breast cancer. PLoS Med 2009;6:e1000068.

51. Imamura $\mathrm{T}$, Hikita $\mathrm{A}$, Inoue $\mathrm{Y}$. The roles of TGF- $\beta$ signaling in carcinogenesis and breast cancer metastasis. Breast Cancer 2012;19:118-24

52. Huang F, Xiao H, Sun BL, Yang RG. Characterization of TRIM62 as a RING finger E3 ubiquitin ligase and its subcellular localization. Biochem Biophys Res Commun 2013:432:208-13.

53. Chen N, Balasenthil S, Reuther J, Killary AM. DEAR1, a novel tumor suppressor that regulates cell polarity and epithelial plasticity. Cancer Res 2014:74:5683-9.

54. Quintás-Cardama A, Zhang N, Qiu YH, Post S, Creighton CJ, Cortes J, et al. Loss of TRIM62 expression is an independent adverse prognostic factor in acute myeloid leukemia. Clin Lymphoma Myeloma Leuk 2015;15:115-27.e15.

55. Quintás-Cardama A, Post SM, Solis LM, Xiong S, Yang P, Chen N, et al. Loss of the novel tumour suppressor and polarity gene Trim62 (Dear1) synergizes with oncogenic Ras in invasive lung cancer. J Pathol 2014:234:108-19.

56. Chen N, Balasenthil S, Reuther J, Frayna A, Wang Y, Chandler DS, et al. DEAR1 is a chromosome 1p35 tumor suppressor and master regulator of TGF- $\beta$-driven epithelial-mesenchymal transition. Cancer Discov 2013;3:1172-89.

57. Wang X, Shi W, Shi H, Lu S, Wang K, Sun C, et al. TRIM11 overexpression promotes proliferation, migration and invasion of lung cancer cells. J Exp Clin Cancer Res 2016;35:100.

58. Di K, Linskey ME, Bota DA. TRIM11 is overexpressed in high-grade gliomas and promotes proliferation, invasion, migration and glial tumor growth. Oncogene 2013:32:5038-47. 
59. Ishikawa H, Tachikawa H, Miura Y, Takahashi N. TRIM11 binds to and destabilizes a key component of the activator-mediated cofactor complex (ARC105) through the ubiquitin-proteasome system. FEBS Lett 2006;580:4784-92.

60. Mittler G, Kremmer E, Timmers HT, Meisterernst M. Novel critical role of a human Mediator complex for basal RNA polymerase II transcription. EMBO Rep 2001;2:808-13.

61. Näär AM, Beaurang PA, Zhou S, Abraham S, Solomon W, Tjian R. Composite co-activator ARC mediates chromatin-directed transcriptional activation. Nature 1999:398:828-32.

62. Kato Y, Habas R, Katsuyama Y, Näär AM, He X. A component of the ARC/Mediator complex required for TGF beta/Nodal signalling. Nature 2002;418:641-6.

63. Zhao M, Yang X, Fu Y, Wang H, Ning Y, Yan J, et al. Mediator MED15 modulates transforming growth factor beta (TGF $\beta$ )/Smad signaling and breast cancer cell metastasis. J Mol Cell Biol 2013:5:57-60

64. Inoue $\mathrm{S}$, Orimo $\mathrm{A}$, Hosoi $\mathrm{T}$, Kondo $\mathrm{S}$, Toyoshima $\mathrm{H}$, Kondo $\mathrm{T}$, et al. Genomic binding-site cloning reveals an estrogen-responsive gene that encodes a RING finger protein. Proc Natl Acad Sci U S A 1993:90:11117-21.

65. Sun N, Xue Y, Dai T, Li X, Zheng N. Tripartite motif containing 25 promotes proliferation and invasion of colorectal cancer cells through TGF- $\beta$ signaling. Biosci Rep 2017;37:BSR20170805.

66. Zhu Z, Wang Y, Zhang C, Yu S, Zhu Q, Hou K, et al. TRIM25 blockade by RNA interference inhibited migration and invasion of gastric cancer cells through TGF- $\beta$ signaling. Sci Rep 2016;6:19070.

67. Nakagawa T, Hosogane M, Nakagawa M, Morohoshi A, Funayama $\mathrm{R}$, Nakayama K. Transforming growth factor $\beta$-induced proliferative arrest mediated by TRIM26-dependent TAF7 degradation and its antagonism by MYC. Mol Cell Biol 2018;38: e00449-17.

68. Chen L, Muñoz-Antonia T, Cress WD. Trim28 contributes to EMT via regulation of E-cadherin and $\mathrm{N}$-cadherin in lung cancer cell lines. PLoS One 2014;9:e101040.

69. Deng B, Zhang S, Zhang Y, Miao Y, Meng X, Guo K. Knockdown of tripartite motif containing 28 suppresses the migration, invasion and epithelial-mesenchymal transition in ovarian carcinoma cells through down-regulation of $\mathrm{Wnt} / \beta$-catenin signaling pathway. Neoplasma 2017;64:893-900.

70. Wei C, Cheng J, Zhou B, Zhu L, Khan MA, He T, et al. Tripartite motif containing 28 (TRIM28) promotes breast cancer metastasis by stabilizing TWIST1 protein. Sci Rep 2016;6:29822.

71. Chen Y, Guo Y, Yang H, Shi G, Xu G, Shi J, et al. TRIM66 overexpression contributes to osteosarcoma carcinogenesis and indicates poor survival outcome. Oncotarget 2015;6:23708-19.

72. Liu Y, Dong Y, Zhao L, Su L, Diao K, Mi X. TRIM59 overexpression correlates with poor prognosis and contributes to breast cancer progression through AKT signaling pathway. Mol Carcinog 2018:57:1792-802.

73. Zhan W, Han T, Zhang C, Xie C, Gan M, Deng K, et al. TRIM59 promotes the proliferation and migration of non-small cell lung cancer cells by upregulating cell cycle related proteins. PLoS One 2015; 10:e0142596.

74. Zhou Z, Ji Z, Wang Y, Li J, Cao H, Zhu HH, et al. TRIM59 is up-regulated in gastric tumors, promoting ubiquitination and degradation of p53. Gastroenterology 2014;147:1043-54.

75. Chen W, Zhao K, Miao C, Xu A, Zhang J, Zhu J, et al. Silencing Trim59 inhibits invasion/migration and epithelial-to-mesenchymal transition via TGF- $\beta /$ Smad2/3 signaling pathway in bladder cancer cells. Onco Targets Ther 2017;10:1503-12.

76. Zhang Y, Yang WB. Down-regulation of tripartite motif protein 59 inhibits proliferation, migration and invasion in breast cancer cells. Biomed Pharmacother 2017;89:462-7.

77. Cai C, Masumiya H, Weisleder N, Matsuda N, Nishi M, Hwang M, et al. MG53 nucleates assembly of cell membrane repair machinery. Nat Cell Biol 2009;11:56-64.

78. Zhao J, Lei H. Tripartite motif protein 72 regulates the proliferation and migration of rat cardiac fibroblasts via the transforming growth factor- $\beta$ signaling pathway. Cardiology 2016;134: 340-6.

79. Li H, Duann P, Lin PH, Zhao L, Fan Z, Tan T, et al. Modulation of wound healing and scar formation by MG53 protein-mediated cell membrane repair. J Biol Chem 2015;290:24592-603. 